\title{
Diagnostic Evaluation of September 29, 2012 Heavy Rainfall Event over Nigeria
}

\section{Akinsanola $\mathrm{AA}^{*}$ and Aroninuola BA}

Department of Meteorology and Climate Science, Federal University of Technology Akure, Nigeria

*Corresponding author: Akinsanola AA, Department of Meteorology and Climate Science, Federal University of Technology Akure, Ondo State, Nigeria. Tel: +2348067112428; E-mail: mictomi@yahoo.com

Received date: January 25, 2016; Accepted date: February 22, 2016; Published date: February 26, 2016

Copyright: @ 2016 Akinsanola AA, et al. This is an open-access article distributed under the terms of the Creative Commons Attribution License, which permits unrestricted use, distribution, and reproduction in any medium, provided the original author and source are credited.

\begin{abstract}
The study diagnostically evaluate the atmospheric conditions that led to the heavy rainfall event of September 29 , 2012 in Nigeria using data from Tropical Rainfall Measurement Mission Multi-Platform Analysis (TMPA 3B43v7) and European Centre for Medium-range Weather Forecast (ECMWF), Era-Interim reanalysis. The spatial pattern of precipitation, horizontal divergence of moisture flux and vertical structure of the zonal wind speed were investigated over the study area. Results show that the heavy rainfall event was only limited to the south of latitude $9^{\circ} \mathrm{N}$ within the study domain. Furthermore, strong moisture convergence (divergence) was observed in the lower (middle) troposphere during the pre-event days of September 27 and 28, 2012, implying strong upward motion of convectively unstable moist air over majority of the study area. This observation may be responsible for the heavy rainfall delivery that led to the flooding. Furthermore, a well-organized African Easterly Jet (AEJ) at 700 hpa and Tropical Easterly Jet (TEJ) at 200 hpa were respectively observed South of $9^{\circ} \mathrm{N}$. It is worthy to note that during the pre-event days, the intensity of the AEJ was greater in magnitude. Disappearing TEJ and a well-organized AEJ was observed North of $9^{\circ} \mathrm{N}$. This observation may be the reason why the heavy rainfall was majorly over South of $9^{\circ} \mathrm{N}$. The distinctive appearance of the two summer easterly Jets South of $9^{\circ} \mathrm{N}$ and the observed moisture convergence at the lower troposphere may have impacted to a very large extent the development of deep moist convection that led to the heavy precipitation experienced over the region. The aforementioned findings may be responsible for the extreme rainfall over the study area.
\end{abstract}

Keywords: Moisture flux; Divergence; African easterly jet; Tropical easterly jet; Heavy rainfall

\section{Introduction}

One of the most crucial and dynamic phenomena of the West African climate system during the summer is the West Africa Monsoon (WAM) $[1,2]$ a phenomenon caused by the seasonal reversal of winds due to differential heating between land and ocean $[3,4]$ it plays a vital role in producing majority of the annual rainfall in the region [5-7]. In general, summer monsoon rainfall in Nigeria usually last between the first week of July until late September [8]. On 29th September, 2012, a heavy rainfall event occurred in major part of Nigeria. Historically, the rainfall recorded was of higher intensity. The Nigeria Meteorological Agency (NIMET) and National Emergency Management Agency (NEMA) reported that the event led to substantial damages (e.g. displacement of thousands of people, loss of crops, homes, farms, belongings, and livelihoods). The effects of the calamity enormously destabilized the economic situation of the Country. Presently, no studies examined the meteorological conditions which produced the September 29, 2012 heavy rainfall. However, such a heavy downpour leading to catastrophic flood disaster deserves a closer look at the atmospheric environment which led to the extreme phenomenon. Such incidences of heavy rainfall need to be monitored regularly in order to avoid the heavy damages that can be caused by subsequent flash flooding. Hence, this study aimed at diagnosing the atmospheric conditions that led to the heavy rainfall event of 29th September, 2012.

\section{Study Area}

Nigeria which lies between latitude $4^{\circ}$ and $14^{\circ} \mathrm{N}$ and longitude $4^{\circ}$ to $14^{\circ} \mathrm{E}$ with elevation ranging from 6 to $1290 \mathrm{~m}$ above, it is bounded on the North by the Republic of Niger, East by Cameroon and West by Benin Republic while the Southern boundary is Gulf of Guinea which is an arm of the Atlantic ocean. There are two main seasons which are wet (June-September) and dry (December-January). These periods vary from the Northern part to the Southern part of the country.

\section{Data and Methodology}

Daily rainfall data used for this study was obtained from the Tropical Rainfall Measurement Mission Multi-Platform Analysis (TMPA 3B43v7) [9,10] from September 27-30, 2012. Also daily zonal and meridional wind components and specific humidity were obtained from the European Centre for Medium-range Weather Forecast (ECMWF), Era- Interim reanalysis dataset for four pressure levels $(1000,850,700$, and $200 \mathrm{hpa})$ for the same time period. It is important to state that all the dataset used were at a spatial resolution of $0.25^{\circ}$ by $0.25^{\circ}$.

Furthermore, the horizontal divergence of moisture flux (HFD) was computed for all the days under study over Nigeria using equation 1.

$$
\mathrm{HFD}=-\left(\left(u \frac{\partial q}{\partial x}+v \frac{\partial q}{\partial y}\right)+\left(q \frac{\partial u}{\partial x}+q \frac{\partial v}{\partial y}\right)\right)(1)
$$

where $\mathrm{q}$ is the specific humidity $(\mathrm{g} / \mathrm{kg}), \mathrm{u}$ and $\mathrm{v}$ are respectively the zonal and meridional wind speed components $(\mathrm{m} / \mathrm{s})$. Negative HFD means convergence while positive means divergence. 
Page 2 of 4

Finally the vertical profile of the zonal wind was plotted to investigate the position and role of the Jet streams.

\section{Results and Discussion}

Before diagnostically evaluating the atmospheric condition that led to the heavy rainfall event. There is need to examine the spatial pattern of rainfall over Nigeria before, during and after the event. September 27 and 28 were used as the pre event days, September, 29 was the event day while September 30 was regarded as the post event day. During the pre-event days there was little or no rainfall in the major part of the country (Figure 1). However, on the day of the event, it was observed that majority of the country experienced rainfall above the daily normal threshold. It is worth mentioning that South of latitude $9^{\circ} \mathrm{N}$ experience rainfall above $120 \mathrm{~mm}$. The intensity of the rainfall had been reduced drastically on the post event day of September 30 .
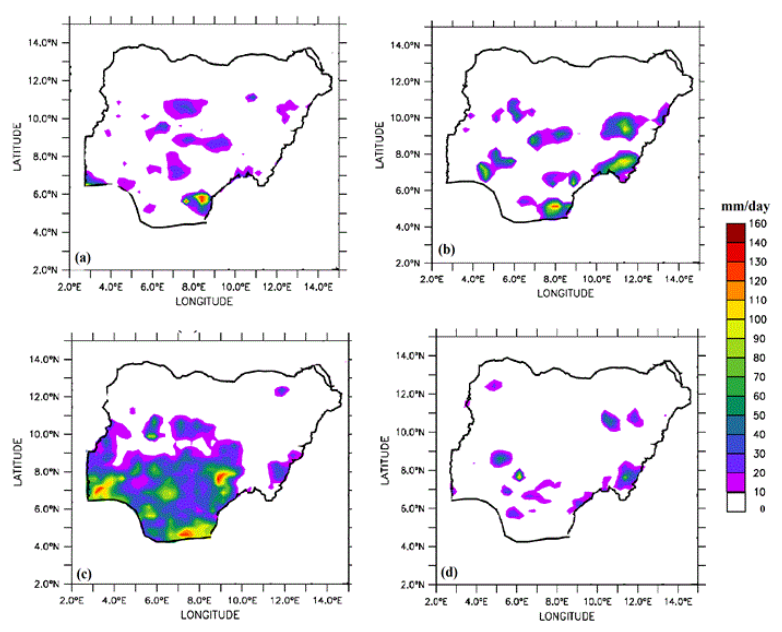

Figure 1: Daily precipitation pattern over Nigeria for the pre event days (a) 27th September, 2012, (b) 28th September, 2012, during the event (c) 29th September, 2012 and post event day (d) 30th September, 2012.

The characteristics of moisture flux at three different tropospheric layers are presented in Figures 2-4. Here the practical usage of equation 1 to diagnose the heavy rainfall event that led to flooding had been displayed. At the surface (1000 hpa), strong moisture convergence was observed on the pre and post event days while dominance of diverging wind was observed in major part of the country on the event day. However, in the middle troposphere (700 hpa), diverging wind with high humidity loadings dominated days 27,28 and 29 . The observed moisture convergence in the lower troposphere and divergence in the middle troposphere during pre-event days may imply strong upward motion of moist air; release of latent heat due to condensation process (this available heat energy might be the source of low-level latent heat instability) and in turn intense rainfall delivery of September 29, 2012. Furthermore, at the upper troposphere, the HFD distribution depicts a wider spread of converging wind over the country in all the days considered. Thus high loading of upper-level moisture transport may have influenced the heavy rainfall South of $9^{\circ} \mathrm{N}$. The results presented here are in mutual agreement with the assumption of Dine's compensation which says "convergence at the surface will lead to divergence at upper level and vice versa".
The dynamics of the atmosphere associated with rainfall over Nigeria is further assessed taking into consideration the zonal wind profile average for two latitudinal domains over Nigeria; South of $9^{\circ} \mathrm{N}$, and North of $9^{\circ} \mathrm{N}$ as shown in Figure 5.
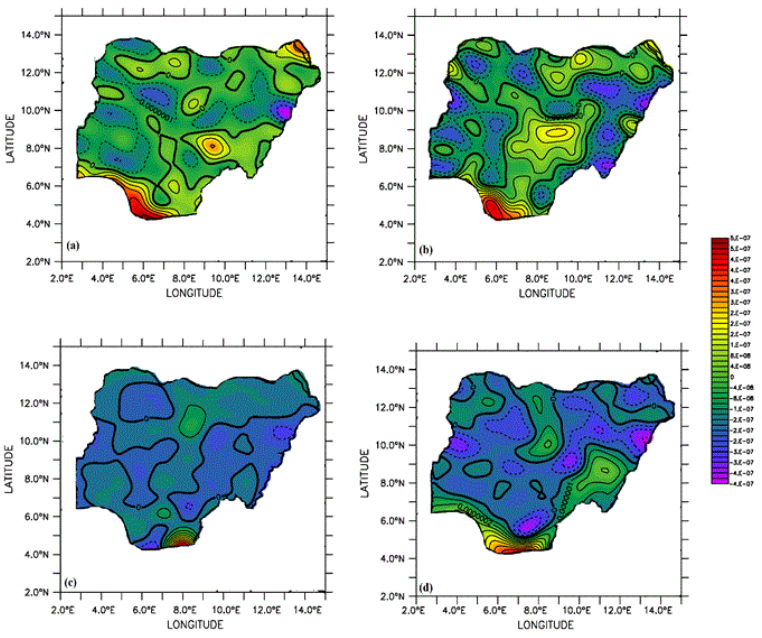

Figure 2: Horizontal Divergence of Moisture flux at 1000 hpa over Nigeria for the pre event days (a) 27th September, 2012, (b) 28th September, 2012, during the event (c) 29th September, 2012 and post event day (d) 30th September, 2012.
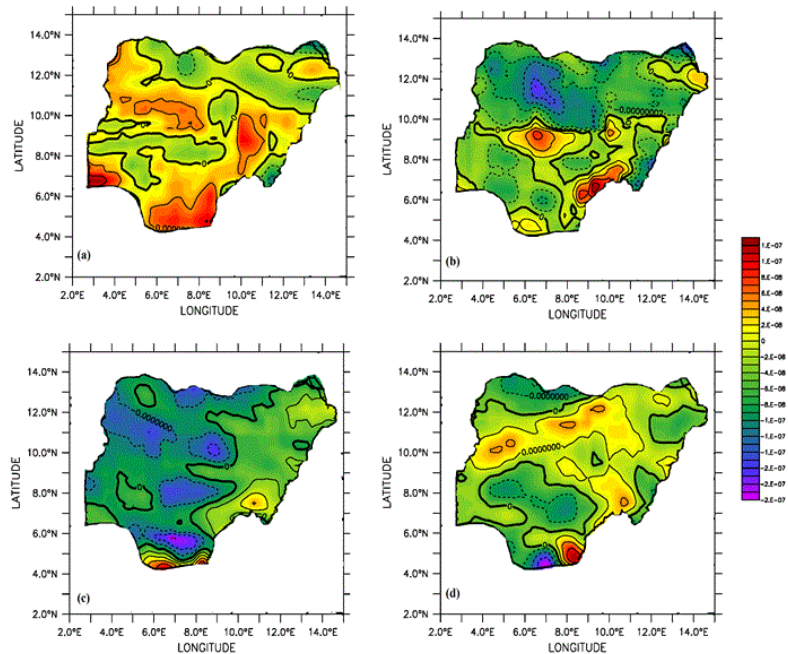

Figure 3: Horizontal Divergence of Moisture flux at 700 hpa over Nigeria for the pre event days (a) 27th September, 2012, (b) 28th September, 2012, during the event (c) 29th September, 2012 and post event day (d) 30th September, 2012. 

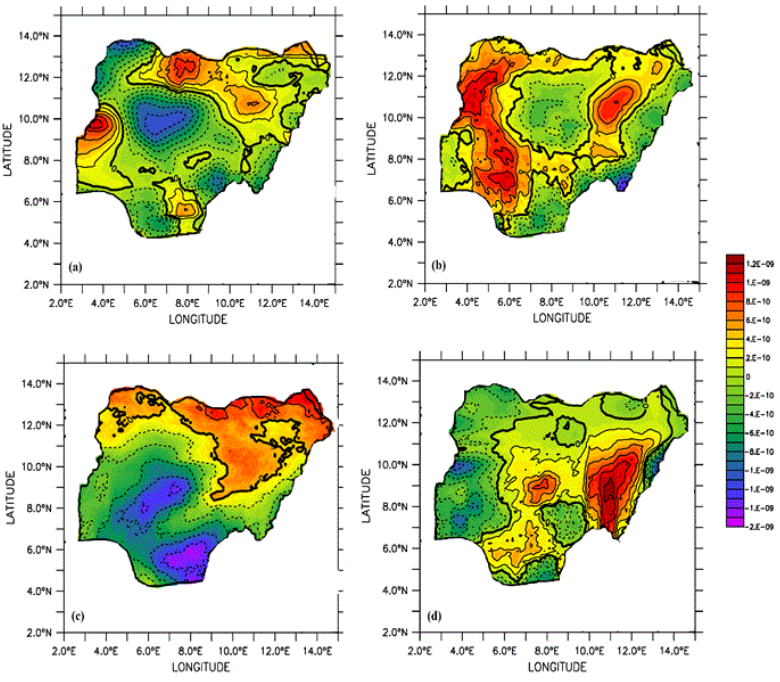

Figure 4: Horizontal Divergence of Moisture flux at 200 hpa over Nigeria for the pre event days (a) 27th September, 2012, (b) 28th September, 2012, during the event (c) 29th September, 2012 and post event day (d) 30th September, 2012..

The diagram illustrates the main dynamical large scale features associated with convective activity and rainfall delivery over Nigeria $[11,12]$. There was an appearance of the African Easterly Jet (AEJ) and Tropical Easterly Jet (TEJ) at 700 hpa and 200 hpa respectively in all five days considered South of $9^{\circ} \mathrm{N}$. However, it is worthy to note that the intensity of the AEJ in the pre event days especially September 28, 2012 was stronger in magnitude $(11 \mathrm{~m} / \mathrm{s})$, with observation of a reasonably distinct TEJ except for day 27 . The zonal wind profile average at North of $9^{\circ} \mathrm{N}$ as shown in Figure $5 \mathrm{~b}$ indicates a deeper moisture depth during the pre-event days with a considerable organised and high magnitude AEJ but with a disappearing TEJ. The disappearance of the Tropical Easterly Jet North of Latitude $9^{\circ} \mathrm{N}$ may be the reason for the little or no rainfall observed over the region. Hence it can be concluded that the combine appearance of a well distinct TEJ and AEJ South of $9^{\circ} \mathrm{N}$ may have impacted to a very large extent the development of deep moist convection that led to the heavy rainfall experienced over the region.

\section{Conclusion}

The atmospheric condition that led to the heavy rainfall event of September 29, 2012 over Nigeria has been diagnosed in this study. The spatial pattern of rainfall over Nigeria indicated that majority of the country experienced rainfall above the daily threshold especially South of $9^{\circ} \mathrm{N}$. Furthermore, the analysis of the horizontal divergence of moisture flux revealed very important characteristics of the heavy rainfall over study region. The observed moisture convergence in the lower troposphere and divergence in the middle troposphere during pre-event days implies strong upward motion of moist air which may be responsible for producing the observed heavy rainfall. Similarly, the occurrence and dominance of the heavy rainfall event South of $9^{\circ} \mathrm{N}$ on 29th September, 2012 may be attributed to a very large extent the appearance of a well-organized and distinct AEJ and TEJ which impacted to the development of deep, moist convection.

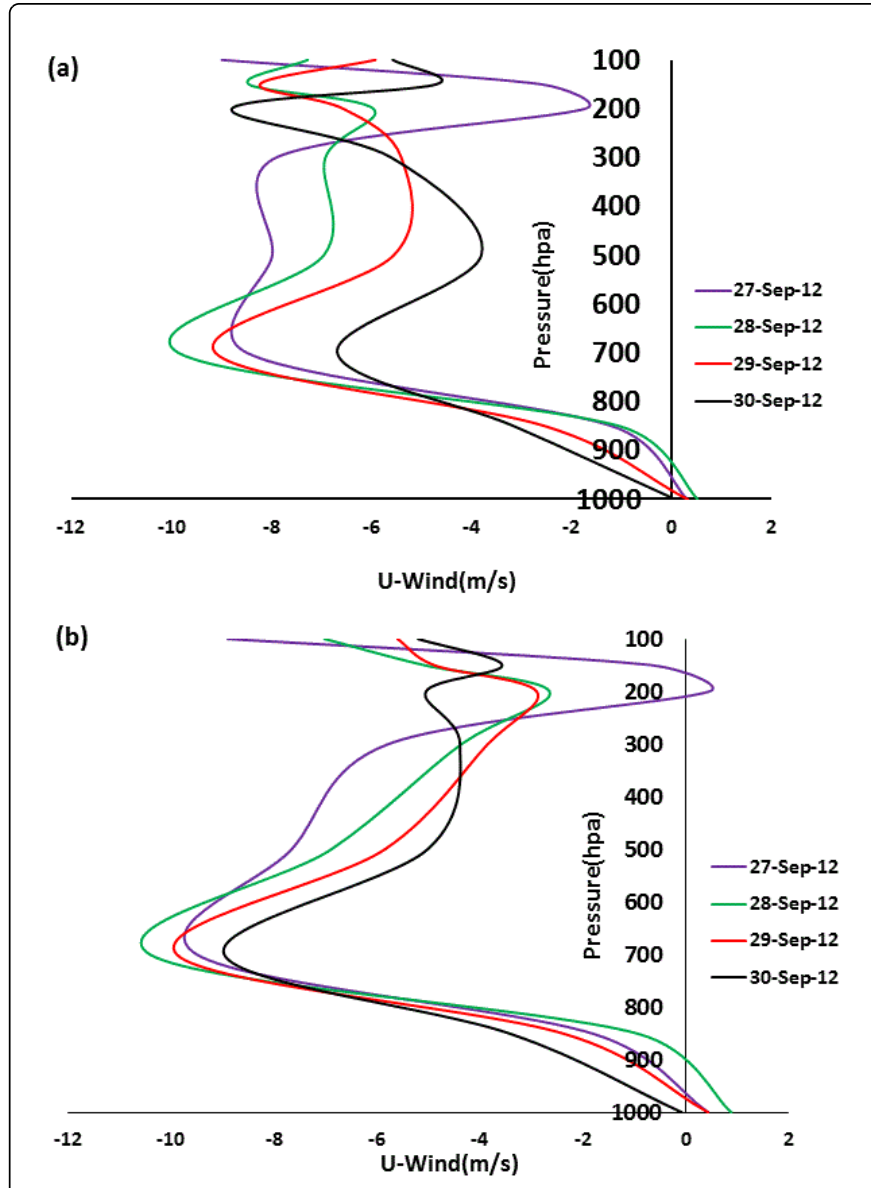

Figure 5: Zonal wind profile over Nigeria average for (a) South of $9^{\circ} \mathrm{N}$ and (b) North of $9^{\circ} \mathrm{N}$.

\section{References}

1. Janicot S, Caniaux G, Chauvin F, de Coetlogon G, Fontaine B, et al. (2010) Intraseasonal variability of the West African monsoon. Atmospheric Science Letters 12: 58-66.

2. Akinsanola AA, Ogunjobi KO, Gbode IE, Ajayi VO (2015) Assessing the Capabilities of three Regional Climate Models over CORDEX Africa in Simulating West African Summer Monsoon Precipitation. Advances in Meteorology 2015: 1-13.

3. Sultan B, Janicot S (2000) Abrupt shift of the ITCZ over West Africa and intraseasonal variability. Geophys Res. Lett 27: 3353-3356.

4. Le Barbe' L, Lebel T (1997) Rainfall climatology of the HAPEX Sahel region during the years 1950-1990. J Hydrol 189: 43-73.

5. Omotosho JB, Abiodun BJ (2007) A numerical study of moisture build-up and rainfall over West Africa. Meteorol Appl 14: 209-225.

6. Omotosho JB (1992) Long-range prediction of the onset and end of the rainy season in the West African Sahel. Int J of Climatology 12: 369-382.

7. Omotosho JB (1990) Onset of thunderstorms and precipitation over Northern Nigeria. International Journal of Climatology 10: 849-860.

8. Akinsanola AA and Ogunjobi KO (2015) Recent Homogeneity Analysis and Long Term Spatio-temporal Rainfall Trends in Nigeria. Theoretical and Applied Climatology 1-15.

9. Kummerow C, Hong Y, Olson WS, Yang S, Adler RF et al. (2001) The evolution of the Goddard profiling algorithm (GPROF) for rainfall 
Citation: Akinsanola AA, Aroninuola BA (2016) Diagnostic Evaluation of September 29, 2012 Heavy Rainfall Event over Nigeria. J Climatol Weather Forecasting 4: 155. doi:10.4172/2332-2594.1000155

Page 4 of 4

estimation from passive microwave sensors. Journal of Appl Met 40: 1801-1840.

10. Huffman GJ, Adler RF, Bolvin DT (2010) The TRMM multisatellite precipitation analysis (TMPA). In satellite rainfall applications for surface hydrology 3-22.
11. Cook KH (1999) Generation of the African Easterly Jet and its role in determining West African precipitation. J Clim 12: 1165-1184.

12. Thorncroft CD, Blackburn M (1999) Maintenance of the African Easterly Jet. Q J R Meteorol Soc 125: 763-786. 